\title{
(RE)ESTRUTURAÇÃO DA CIDADE E AS NOVAS EXPRESSÕES DE CENTRALIDADE URBANA NA CIDADE DE ANANINDEUA, AMAZÔNIA PARAENSE
}

\author{
Jovenildo Cardoso Rodrigues \\ Professor do Programa de Pós-Graduação em Geografia \\ Universidade Federal do Pará (UFPA) \\ jovengeo@yahoo.com.br \\ Leide Laura de Carvalho Rodrigues \\ Mestre em Geografia pelo Programa de Pós-Graduação em Geografia \\ Universidade Federal do Pará (UFPA) \\ leide.laura87@outlook.com
}

\begin{abstract}
RESUMO
As cidades brasileiras, entre elas as amazônicas, vêm passando por múltiplas, sucessivas e complexas transformações socioespaciais no limiar do século XXI. Tais transformações encontram-se vinculadas à urbanização do território, (re)estruturação de cidades metropolitanas e não metropolitanas. Situada na Amazônia Paraense, a cidade de Ananindeua revela-se, no momento atual, como espaço de intensas "metamorfoses" socioespaciais, associadas a ações do Estado, a territorialização de novos agentes econômicos do comércio e serviços, que atuam em múltiplas escalas. O presente artigo objetiva analisar de que maneira os novos agentes de comércio e serviços vem interferindo na (re)estruturação da cidade e na (re)produção do centro e da centralidade urbana em Ananindeua-PA, a partir dos anos de 2000. Quanto aos procedimentos metodológicos, realizou-se levantamento bibliográfico e documental, observações sistemáticas qualitativas, registros fotográficos, produção cartográfica e entrevistas semiestruturadas. A pesquisa evidenciou que a territorialização de novos agentes de comércio e serviços em Ananindeua vem contribuindo para a ampliação da divisão social desigual do espaço da cidade, para mudanças aceleradas nas estruturas urbanas e para a constituição de uma cidade "multi(poli)cêntrica", caracterizada por múltiplos centros, diversas centralidades urbanas e pela coexistência de tempos, temporalidades e espacialidades urbanas diferentes, diversas e desiguais.
\end{abstract}

Parlavras-Chave: Centro e Centralidade Urbana. (Re)estruturação da Cidade. Cidades Amazônicas. Ananindeua.

\section{(RE) STRUCTURING THE CITY AND THE NEW EXPRESSIONS OF URBAN CENTRALITY IN THE CITY OF ANANINDEUA, AMAZÔNIA PARAENSE}

\begin{abstract}
Brazilian cities, including the Amazon, have been going through multiple, successive and complex socio-spatial transformations at the threshold of the 21 st century. These transformations are linked to the urbanization of territory, (re)structuring of metropolitan and non-metropolitan cities. Located in the Amazon region of Pará, the city of Ananindeua is currently experiencing intense socio-spatial "metamorphoses" associated with state actions, the territorialisation of new economic agents of commerce and services, which operate on multiple scales. The present article aims to analyse how the new agents of commerce and services have interfered in the (re)structuring of the city and in the (re)production of the urban centre and centrality in Ananindeua-PA, since the years 2000. As for methodological procedures, bibliographic and documentary surveys, qualitative systematic observations, photographic records, cartographic production and semi-structured interviews were carried out. The research showed that the territorialisation of new agents of commerce and services in Ananindeua has contributed to the widening of the unequal social division of city space, to accelerated changes in urban structures and to the constitution of a "multi(poli)centric" city, characterised by multiple centres, diverse urban centralities and the coexistence of different, diverse and unequal urban times, temporalities and spatialities.
\end{abstract}

Keywords: Center and Urban Centralization. City (Re)structuring. Amazon Cities. Ananindeua. 


\section{INTRODUÇÃO}

As cidades brasileiras, entre elas as amazônicas, vem passando por sucessivas, múltiplas e complexas transformações socioespaciais vinculadas ao processo de mundialização do capital, (RODRIGUES, 2015; RODRIGUES, 2020), urbanização extensiva do território (MONTE MOR, 2014), (re)estruturação de cidades metropolitanas e não metropolitanas, bem como, reconfigurações da rede urbana (RODRIGUES, 2015). Tais elementos encontram-se relacionados à inserção da região Amazônica à economia global e às determinações da produção capitalista do espaço, com reverberações significativas na intensificação de diferenciações na morfologia urbana de centros e periferias de cidades, assim como, na constituição de novas centralidades urbano-regionais (RODRIGUES, 2015).

Para Keil (2018), o recente movimento e dinamicidade da urbanização contemporânea evidencia uma variedade e diversidade de morfologias, infraestruturas, dinâmicas compostas por múltiplas centralidades e descentralidades, face a uma "sociedade completamente urbanizada". Lefebvre (2014) já assinalava possíveis resultados negativos de uma urbanização planetária, cuja força homogeneizadora, seria capaz de reduzir todos os espaços ao valor de troca, ao aniquilamento da diversidade, reforçando hierarquias, desigualdades, segregações e exclusões.

Em escala local, a cidade de Ananindeua, situada na Região Metropolitana de Belém - RMB, Amazônia Paraense (Ver Mapa 1), constitui-se espaço de intensas "metamorfoses" socioespaciais, no início do século XXI, como resultado dos processos de metropolização do espaço, de urbanização, de (re)estruturação urbana e da cidade (RODRIGUES; SOBREIRO FILHO, OLIVEIRA NETO, 2018), bem como, de ações do Estado, de novos agentes econômicos e agentes sociais excluídos, cujas manifestações particulares permitem expressar uma nova condição espacial da referida cidade, como espaço no qual as estruturas urbanas revelam a um só tempo, a (re)produção de novas centralidades urbanas, a coexistência de tempos, ritmos, movimentos, temporalidades e espacialidades urbanas diferentes, diversas e desiguais.

As formas e morfologias urbanas de Ananindeua permitem evidenciar um mosaico de elementos estruturantes, a saber: intensificação do uso solo urbano, especulação imobiliária, ampliação de divisão social desigual do espaço, elevação dos índices de violência urbana, crescimento demográfico acelerado, incremento considerável de atividades comerciais e de serviços, expansão da produção habitacional, avanço de mercado de terras, forte presença de construtoras na produção de condomínios residenciais fechados, avanço de novos agentes econômicos vinculados ao terciário e terciário avançado, ampliação de diferenciações e desigualdades socioespaciais (RODRIGUES; SOBREIRO FILHO; OLIVEIRA NETO, 2018). Tais elementos assemelham-se a tendências e padrões mundiais em termos de apropriação e uso no espaço das cidades (HARVEY, 2018; HARVEY, 2019a; 2019b)

Considerando tais formas, processos, estruturas e morfologias urbanas e buscando capturar e/ou compreender esta porção territorial, em sua relação entre universalidades, particularidades e singularidades, o presente artigo objetiva analisar de que maneira os novos agentes de comércio e serviços vem interferindo na (re)estruturação da cidade e na (re)produção do centro e da centralidade urbana em Ananindeua-PA, a partir dos anos de 2000.

A metodologia enquanto construção do processo de pesquisa aqui apresentado teve como objeto de estudo, reestruturação da cidade, o centro e a centralidade urbana, a partir de uma abordagem quantitativa e qualitativa. Para tanto, os conceitos de centro, centralidade urbana e reestruturação da cidade foram acionados como alicerces conceituais, que em sua relação dialética e dialógica com a realidade empírica, possibilitou uma análise da cidade e do urbano, bem como, das novas expressões do centro e da centralidade urbana do comércio e serviços em Ananindeua no período atual.

Soja (1993) considera que a reestruturação não constitui elemento mecânico ou automático, nem tampouco seus resultados e possibilidades potenciais são predeterminados. Tal processo deve ser considerado, a um só tempo, como proveniente e reagente a graves choques imanentes a circunstâncias contingentes e não contingentes, além de práticas sociais e espaciais preexistentes, que tendem a desencadear intensas lutas competitivas pelo controle das forças que configuram a vida urbana. Sposito (2004) afirma que a expressão reestruturação deve ser guardada, a fim de que façamos referência aos períodos nos quais o conjunto das mudanças que orientam os processos de estruturação urbana e estruturação das cidades foram amplos e profundos. 
A respeito dos conceitos de centro e centralidade, Sposito (2013) enfatiza que o centro pode ser compreendido como o fixo, constituindo-se de configurações territoriais, práticas espaciais materializadas em rugosidades, expressas na produção territorial da cidade. Ainda para a referida autora, a centralidade constitui-se um conjunto de fluxos, que se projetam e se articulam com o centro e se irradiam no contexto das redes urbanas.

Do ponto de vista do processo de pesquisa, efetuou-se uma breve, porém importante periodização histórico-geográfica sobre a formação da cidade de Ananindeua, de maneira a identificar eventos, tempos, temporalidades, processualidades e espacialidades urbano-regionais que interferiram nas múltiplas, sucessivas e por vezes simultâneas divisões territoriais do trabalho, bem como, as configurações territoriais (SANTOS, 1996) e coexistências concernentes a produção da cidade e do urbano na Amazônia e em Ananindeua.

A abordagem teórico-metodológica pautou-se em uma análise do movimento de contradições inerentes à produção do espaço urbano, que para Lefebvre (1991) constitui possibilidade analítica importante para uma reflexão acerca do objeto em movimento, atentando para o desenvolvimento de múltiplas determinações da realidade social, de tal maneira que possamos identificar movimentos de transformações que conduziram a mudanças gerais, às particularidades e singularidades. As escalas temporal, cartográfica e geográfica foram acionadas de maneira a se promover uma análise das transformações territoriais no espaço metropolitano ananindeuense. Como procedimentos metodológicos, realizou-se levantamento e análise bibliográfica de livros, dissertações, teses, além de periódicos nacionais e internacionais para a construção da pesquisa. Efetuou-se ainda levantamento e análise de documentos como: Plano Diretor e diagnóstico do Plano Diretor de Ananindeua, dados demográficos do Instituto Brasileiro de Geografia e Estatística - IBGE, visitas na Secretaria Municipal de Saneamento e na Secretaria Municipal de Habitação e Interesse Social da Prefeitura de Ananindeua de maneira a coletar informações qualitativas e quantitativas.

Ao longo de dois anos de pesquisa (2018 e 2019) realizou-se seis trabalhos de campo, com os seguintes procedimentos metodológicos: Observações sistemáticas qualitativas, registros fotográficos nos espaços centrais e nas franjas urbanas desta cidade, de maneira a subsidiar a fundamentação das ideias apresentadas nesta pesquisa. Tais elementos metodológicos fizeram-se de grande importância enquanto possibilidades para identificar um conjunto de dinâmicas espaciais, movimentos e ritmos da cidade como expressões dos centros, centralidades urbanas.

A produção cartográfica constituiu-se instrumento fundamental para análise da morfologia urbana e das estruturas urbanas em Ananindeua. Neste sentido, realizou-se produção cartográfica utilizando imagens de satélite com bases vetoriais do IBGE e Landsat 5,8. Finalmente, a realização de entrevistas semiestruturadas com moradora da Cidade de Marituba (localizada na Região Metropolitana de Belém) e frequentadora cotidiana dos espaços de comércio e serviços na cidade de Ananindeua, com representante do poder público municipal e com morador e representante de serviço público municipal. As referidas entrevistas possibilitaram apreender as dinâmicas aceleradas de transformações no espaço geográfico ananindeuense a partir de narrativas e experiencias dos sujeitos, tornando possível uma leitura dos centros e centralidades urbanas a partir do espaço vivido.

O artigo encontra-se subdividido em seis momentos: um primeiro momento constituído desta pequena introdução, na qual delineamos os caminhos do processo de pesquisa. O segundo momento é marcado por breves considerações a respeito da formação da centralidade urbana da cidade de Ananindeua. O terceiro momento propõe uma análise do centro e da centralidade urbana, de maneira a apresentar algumas dinâmicas da Estrutura espacial e Morfologia Urbana do Espaço Metropolitano Ananindeuense. O quarto momento aborda a (re)estruturação das formas urbanas da cidade de Ananindeua, a partir de uma leitura da morfologia das novas dinâmicas de comércio e dos serviços urbanos, como elementos que ajudam a entender $o$ centro $e$ as novas expressões da poli(Multi)centralidade na respectiva cidade. $O$ quinto momento está delineado a partir de análises das entrevistas, de maneira a revelarmos algumas expressões do Centro e da Centralidade Urbana em Ananindeua. Por fim, o sexto momento constitui as considerações finais, ocasião de síntese, construção de reflexões, proposições e pistas/indagações para novas pesquisas. 
Figura 1 - Ananindeua (PA): Situação geográfica do Município e da Cidade, 2019.

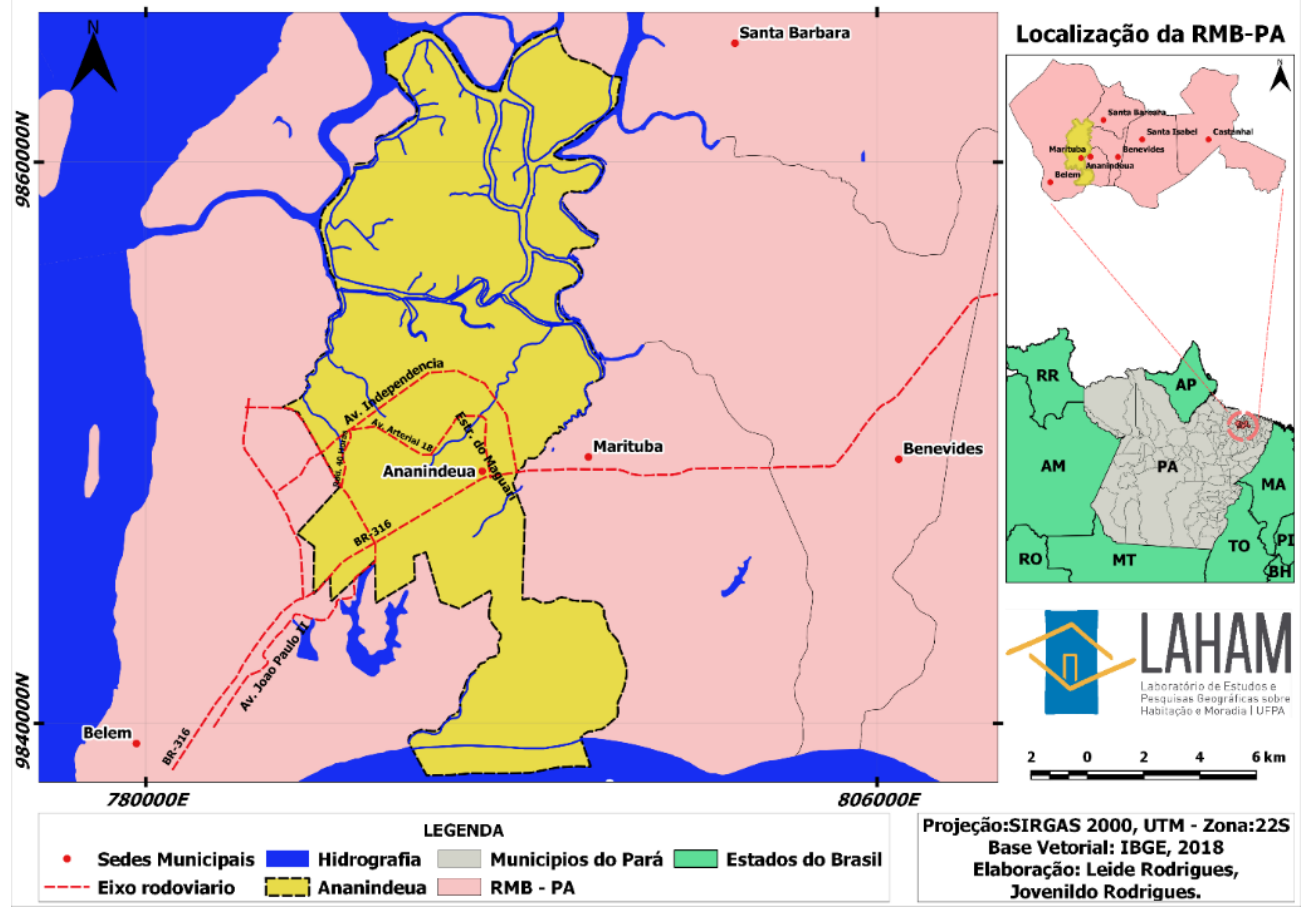

Fonte - Elaborado pelos autores do artigo

\section{ELEMENTOS DE FORMAÇÃO DA CENTRALIDADE URBANA DE ANANINDEUA}

A formação da centralidade da cidade de Ananindeua foi delineada aqui a partir de uma pequena e breve periodização, que não tem o propósito de estabelecer maiores detalhamentos acerca da formação da cidade de Ananindeua. Não obstante, a periodização constitui recurso metodológico importante para se trazer à tona alguns elementos que permitem pensar a cidade em seus tempos, eventos, temporalidades, coexistências, espacialidades urbanas diferentes, diversas e desiguais, considerando suas particularidades, universalidades e singularidades (SANTOS, 1996; RODRIGUES, 2015). Dito isto, definimos tal periodização considerando a articulação entre as determinações relacionadas a mudanças nas formas, funções, estruturas, processos na escala do espaço urbano e a inserção de novos sistemas técnicos, no território amazônico. Tal escolha decorre da compreensão de que os referidos sistemas técnicos, enquanto um conjunto indissociável e dialético de "Sistemas de Objetos e Sistemas de Ações" constituintes e constituidores do espaço socialmente produzido (SANTOS, 1996), exerceram papel significativo como elementos estruturantes na produção de ações e de eventos que interferiram na produção no território amazônico.

Assim, definimos uma periodização considerando eventos, processos e ações estruturantes, da seguinte maneira: 1) O período que compreende entre o final do século XIX até os anos de 1950, marcado pela centralidade de Ananindeua, produzida a partir da implantação da Estrada de Ferro de Bragança (E.F.B.); 2) O período que compreende entre os anos de 1960 e 1970, caracterizado pela centralidade de Ananindeua, constituída a partir da implantação do Eixo Rodoviário da BR-316; 3) O período entre os anos de 1980 e 1990, configurado a partir da urbanização extensiva, pela dispersão metropolitana de Belém, com esgarçamento do tecido metropolitano e Estruturação da cidade de Ananindeua; 4) O período que compreende entre os anos de 2000 a 2019, momento em que as paisagens e morfologias urbanas permitem revelar a $(R e)$ Estruturação da cidade, a partir da coexistências entre antigas e novas espacialidades urbanas e suas expressões no centro e na centralidade de Ananindeua.

O período que compreende entre o final do século XIX até os anos de 1950 configura momento de transformações no território amazônico, com repercussões em espaços como o que hoje corresponde o município de Ananindeua. O "boom" da atividade da borracha na Amazônia, sobretudo a partir do final do século XIX, fortemente estimulado pelo processo de crescimento da indústria automobilística nos países desenvolvidos, contribuiu significativamente para induzir uma divisão territorial do trabalho na Amazônia e incorporação de novos sistemas técnicos no território amazônico (WIENSTEIN, 1993). $\mathrm{Na}$ escala do território paraense, ocorreu impulso vigoroso a urbanização da capital paraense, fato

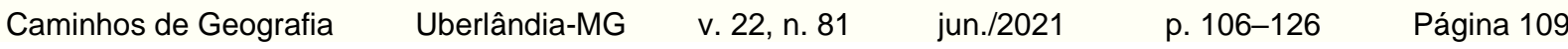


que repercutiu em elevado crescimento econômico e demográfico na cidade de Belém, com aumento das demandas por produtos agrícolas (PENTEADO, 1967).

Em escala local, a formação do então povoado de Ananindeua, pertencente na época ao território de Belém, no final do século XIX estava vinculado a estratégias e ações do governo provincial, visando estimular o processo de colonização de terras férteis na Zona Bragantina, bem como, incrementar a produção de alimentos de maneira a atender ao mercado regional e da capital paraense, Belém (MOREIRA, 1989). É neste sentido, que o referido povoado foi alçado à condição de "Ponta de Trilho" da referida Estrada de Ferro de Bragança (E.F.B.) (PENTEADO, 1967), no ano de 1884, com a inauguração dos primeiros 14 quilômetros da E.F.B. que ligaria Belém ao povoado de Ananindeua (ANANINDEUA, 2006; RODRIGUES SOBREIRO FILHO; OLIVEIRA NETO, 2018).

Tal evento possibilitou a implantação de colônias agrícolas e o surgimento de povoados nas imediações das paradas da Estrada de Ferro de Bragança (PENTEADO, 1967), configurando um processo paulatino de formação da centralidade urbana induzida pela presença por essa Estrada. No início do século XX, o pequeno povoado de Ananindeua, constituído nas imediações da E.F.B., logo ganharia novas dimensões (ANANINDEUA, 2006).

O período que compreende entre as décadas de 1920 e 1950, na escala da Amazônia brasileira, é compreendido como um momento de decadência econômica e da rede urbana amazônica, em razão do declínio da atividade da borracha (CORREA, 1988). Não obstante, na escala local, a instalação e funcionamento da Estrada de Ferro Belém-Bragança-E.F.B, enquanto sistema técnico associado a uma ordem exógena ao lugar, contribuiu para a produção de uma divisão territorial do trabalho, que consistiu na constituição de novas incorporações territoriais, vinculadas aos interesses do capital, bem como, na produção de diferenciações socioespaciais, urbanidades e centralidades que passaram a se desenvolver, vinculados não apenas a valores de uso, mas também a valores de troca (PENTEADO, 1968; RODRIGUES; SOBREIRO FILHO; OLIVEIRA NETO, 2018).

De um ponto de vista político-institucional, até o início da década de 1940, Ananindeua se constituía apenas em distrito do município de Belém. No ano de 1943, o Interventor Federal Magalhães Barata promulgou a criação do município de Ananindeua, por meio do Decreto-Lei oㅜ 4.505 (ANANINDEUA, 2006). Não obstante, sua sede municipal foi reconhecida como cidade apenas no dia 31 de dezembro de 1947, sendo composta pela sua sede e pelos distritos de Benevides, Benfica e Engenho Arari (ANANINDEUA, 2006). A distribuição populacional do município de Ananindeua, segundo o Censo de 1950 indicava a clara condição de município eminentemente rural, uma vez que, dos seus 13.303 habitantes, aproximadamente 1.000 pessoas ocupavam as cerca de 120 casas existentes na sede municipal (ANANINDEUA, 2006).

Do ponto de vista de sua dinâmica de centro econômico-industrial, entre os anos de 1940 e 1950, convém ressaltar que Ananindeua logo passou a apresentar a condição de terceiro maior município do estado do Pará em número de indústrias, tendo no Curtume Maguari a sua mais expressiva representação, considerado um dos mais importantes estabelecimentos industriais do Norte do País. Do ponto de vista demográfico, segundo estimativa do então Departamento Estadual de Estatística, a população do município, no ano de 1956, havia chegado aos 14.995 habitantes, sendo 7.601 residentes no Distrito Sede de Ananindeua (cerca de 50\% da população), 2.316 no Distrito de Benevides, 2.347 no Distrito de Benfica e 2.731 no Distrito de Engenheiro Araci (ANANINDEUA, 2006).

O período que compreende entre os anos de 1960 a 1970 corresponde momento de transformações aceleradas no espaço regional amazônico, como resultado de um rápido processo de urbanização induzida pelo Estado, a partir de políticas de planejamento, que objetivavam promover a incorporação da fronteira urbana amazônica no contexto da divisão territorial do trabalho, por meio de uma política de Integração Nacional que incorporou o novo modelo de integração nacional baseado nas redes rodoviárias (RODRIGUES, 2015).

Tal política contribuiu para a extinção da E.F.B. no ano de 1964, fato que implicou em mudança na dinâmica de transporte nos municípios como Belém, Ananindeua, Marituba, Benevides, Santa Isabel, Castanhal, dentre outros municípios que tinham seus fluxos de transportes de pessoas, mercadorias e serviços associados ao modelo ferroviário (PENTEADO, 1967; BECKER, 1990; RODRIGUES, 2015). O avanço dos processos de urbanização do território e de reorganização da rede urbana paraense teve sua expressão na produção do espaço metropolitano belenense, com crescimento demográfico e espacial de cidades como Belém e Ananindeua, Castanhal, Marabá, Santarém, Altamira, bem como, de novas configurações da morfologia urbana e produção de centralidades nas respectivas cidades amazônicas (RIBEIRO, 2017; RODRIGUES; SOBREIRO FILHO; OLIVEIRA NETO, 2017). 
$\mathrm{Na}$ escala da cidade de Ananindeua, os anos de 1980 e 1990 são marcados por intensas transformações associadas aos efeitos da urbanização extensiva, da dispersão metropolitana e da estruturação da cidade, dentre os quais podemos elencar: 1) áreas do município de Ananindeua consideradas rurais, por parte do poder público, passaram a ser incorporadas rapidamente ao perímetro urbano do munić́pio ; 2) o espaço urbano de Ananindeua se consolidou e se transformou rapidamente diante dos impulsos vinculados a implantação dos conjuntos habitacionais (RODRIGUES, 1998) ${ }^{1}$; 3) rápido incremento populacional no município - mudanças significativas nas estruturas e na morfologia urbana de Ananindeua; 4) Ananindeua passou a exercer a função de "cidade dormitório", de maneira a atender as demandas da metrópole belenense. Do ponto de vista demográfico, o gráfico 1, extraído a partir dos censos do IBGE, permite expressar a dinâmica populacional do município de Ananindeua, no período entre os anos de 1980 e começo dos anos de 1990, possibilitando identificarmomento de inflexão, quando então a população urbana supera a população rural em número de habitantes.

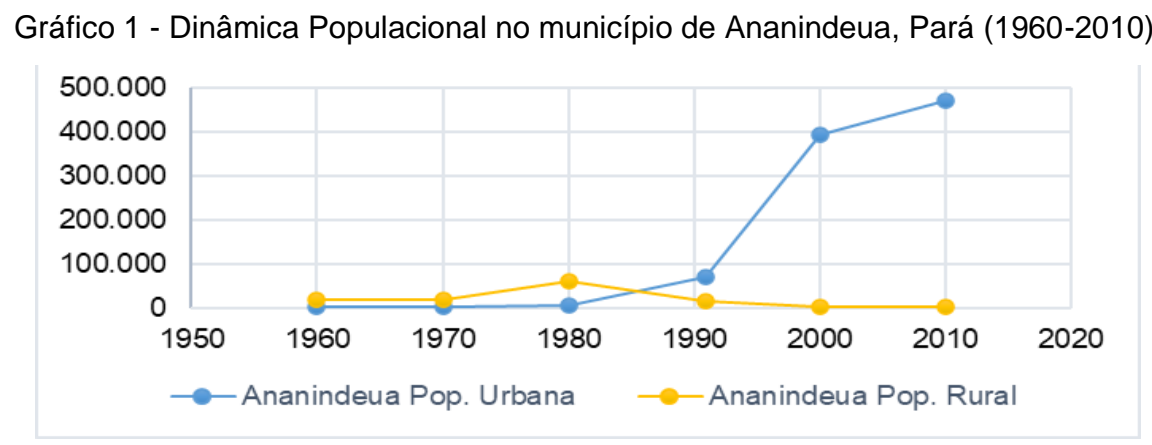

Fonte - Elaborado pelos autores com base no IBGE.

A tabela 1 permite ilustrar uma aceleração das taxas de urbanização no município de Ananindeua, que saltou de $10,4 \%$, na década de 1980 , para $79,5 \%$, na década de 1990 , possibilitando demonstrar a intensidade do crescimento demográfico. Uma outra tendência importante evidenciada nos dados dos censos, expressos na tabela 2, diz respeito ao crescimento da população total no município, que saltou de pouco mais de 80.000 habitantes, no ano de 1991, para quase 400.000 habitantes, nos anos de 2000; fato que demonstra a acelerada dinâmica populacional em direção ao referido município da Região Metropolitana de Belém (R.M.B.). A tabela 2 permite ilustrar, ainda, que o referido município apresenta uma elevada taxa de urbanização da ordem de $99,8 \%$ para o ano de 2010.

Tabela 1 - Ananindeua (PA): Dinâmica populacional no município, 1960-2010.

\begin{tabular}{ccccc}
\hline Período & Pop. Urbana & $\begin{array}{c}\text { Pop. } \\
\text { Total }\end{array}$ & $\begin{array}{c}\text { Taxa de } \\
\text { Urbanização }\end{array}$ & Pop. Rural \\
\hline 1960 & 3.353 & 20.330 & $16,5 \%$ & 16.977 \\
1970 & 2.916 & 22.527 & $12,9 \%$ & 19.611 \\
1980 & 6.858 & 66.027 & $10,4 \%$ & 59.169 \\
1991 & 70.051 & 88.151 & $79,5 \%$ & 14.100 \\
2000 & 392.627 & 393.569 & $99,8 \%$ & 942 \\
2010 & 470.819 & 471.980 & $99,8 \%$ & 1.161 \\
\hline \multicolumn{7}{c}{ Fonte - IBGE. Censos Demográficos (1960, 1970, 1980, 1991, 2000, 2010) }
\end{tabular}

\footnotetext{
1 O diagnóstico do Plano Diretor Urbano de Ananindeua, realizado no ano de 2006, subdividiu a sede municipal em Bairros da seguinte maneira: Cidade Nova 1, Cidade Nova 2, Cidade Nova 3, Cidade Nova 4, Cidade Nova 5, Cidade Nova 6, Cidade Nova 7, Cidade Nova 8, Jaderlândia, Guajará, PAAR, Atalaia, 40 Horas, Geraldo Palmeira, Guanabara, Heliolândia, Coqueiro, Icuí-Guajará, Aura, Águas Brancas, Maguarí, Providência, Águas Lindas, Jibóia Branca, Centro e Julia Seffer, Curuçambá, Icuí-Laranjeiras e o Distrito Industrial (ANANINDEUA, 2006).
} 
Os dados demográficos permitem ilustrar algumas tendências no sentido de identificarmos o papel que passou a ser exercido pela cidade de Ananindeua, no contexto de estruturação da cidade, nos anos de 1980 e 1990. A rápida mudança nas estruturas urbanas de Ananindeua denota a constituição de uma cidade que passou por rápido processo de estruturação, tanto nas formas urbanas quanto nos conteúdos socioespaciais, de maneira a atender a lógicas e racionalidade do Estado e do mercado.

O período que compreende entre os anos de 2000 a 2019, na escala regional amazônica, constitui momento marcado pela recente urbanização extensiva, relacionada a (re)estruturação urbana metropolitana (MONTE-MOR, 2014; VIEIRA, RODRIGUES, RODRIGUES, 2017), bem como, por uma sucessão de rupturas e metamorfoses socioespaciais relacionadas ao processo de "Spreading the Metropolitan Form", como meio, condição e produto de novas dinâmicas urbanas associadas à "produção capitalista do espaço", a ações do Estado, do mercado e de agentes sociais excluidos.

$\mathrm{Na}$ escala da cidade de Ananindeua, o período que compreende entre os anos de 2000 a 2019 tem sido marcado por uma uma sucessão de permanências, rupturas e metamorfoses nas formas e morfologias urbanas da cidade, como resultado das novas configurações territoriais associadas ao processo de (re)estruturação urbana e da cidade (RODRIGUES, 2020).

Como expressões deste processo, podemos identificar uma reconfiguração do centro e novas formas de centralidade urbana, a partir da presença de novos agentes econômicos (Hipermercados, Shoppings centers, construtoras e incorporadoras), vinculados ao capital nacional e internacional, forte presença do Estado na condução de um ordenamento territorial, (construção de BRT metropolitano), constituição e implantação de novos eixos estruturantes de maneira a impulsionar novas conexões, novos fluxos de pessoas, mercadorias, serviços urbanos e informações.

O breve resgate histórico-geográfico, a respeito de alguns momentos de formação da centralidade urbana de Ananindeua, não tem a pretensão de esgotar o complexo debate acerca da formação da cidade. Buscamos tão somente situar o leitor no debate, para apresentar algumas expressões da centralidade urbana no período atual. A esse respeito, delineamos algumas reflexões a seguir.

\section{DINÂMICAS DA ESTRUTURA ESPACIAL E MORFOLOGIA URBANA DO ESPAÇO METROPOLITANO ANANINDEUENSE}

Entender as antigas e recentes espacialidades urbanas vinculadas à produção dos centros e novas centralidades urbanas em Ananindeua, no período contemporâneo, requer que façamos uma abordagem acerca das dinâmicas de usos do solo nesse espaço, atentando para as características de expansão da macha urbana, bem como para a importância dos Eixos Estruturantes e da Morfologia Urbana. Isso para uma compreensão da nova condição espacial desta cidade metropolitana, que vem passando por uma sucessão de descontinuidades e rupturas profundas, associadas ao avanço dos processos de urbanização do território, reestruturação metropolitana e reestruturação da cidade (RODRIGUES; SOBREIRO FILHO; OLIVEIRA NETO, 2018).

A Morfologia urbana consiste em perspectiva analítica que pode auxiliar em uma análise explicativa acerca das "metamorfoses" em cidades, por meio de uma investigação sobre as mudanças e permanências, continuidades e rupturas, nas formas espaciais e suas relações com as determinações processuais que interferem na produção do espaço da cidade capitalista (CAPEL, 2013; SCOTT, 2014). Para Capel (2013), a morfologia urbana refere-se ao espaço construído e reflete a organização econômica, social, as estruturas políticas, bem como, os objetivos de grupos sociais dominantes.

Sposito (2017) enfatiza que a análise da morfologia urbana pressupõe considerar a forma como um dos elementos constituintes da morfologia, o plano urbano como arcabouço dessa forma, assim como a extensão urbana, enquanto elementos designativos da morfologia de uma cidade. Sposito (2004); 
Miyazaky (2018) afirmam que a morfologia urbana necessita ser apreendida a partir de uma abordagem mais ampla, que considere as formas urbanas, mas também os conteúdos inerentes aos processos de gênese e desenvolvimento de cidades, de maneira que se possa explicar a morfologia e não apenas descrevê-la ou representá-la.

Do ponto de vista empírico, acionamos a produção cartográfica como estratégia de pesquisa para construção de algumas interpretações e análises a respeito da Morfologia urbana da cidade de Ananindeua. A esse respeito, a Figura 2 (mapa) permite identificar a dinâmica da cobertura vegetal e uso do solo em Ananindeua, entre os anos de 1984 a 2019. Ao comparamos as imagens de satélite, do ano de 1984 com a do ano de 2019, evidenciamos a ocorrência de aumento significativo da área edificada no município de Ananindeua, que saltou de $17 \%$, em 1984, para 31\%, no ano de 2019. Fato que representou crescimento da área edificada na ordem de $87,06 \%$.

Figura 2 - Ananindeua (PA): Dinâmica da Cobertura vegetal e Uso do Solo em Ananindeua, 1984-2019.
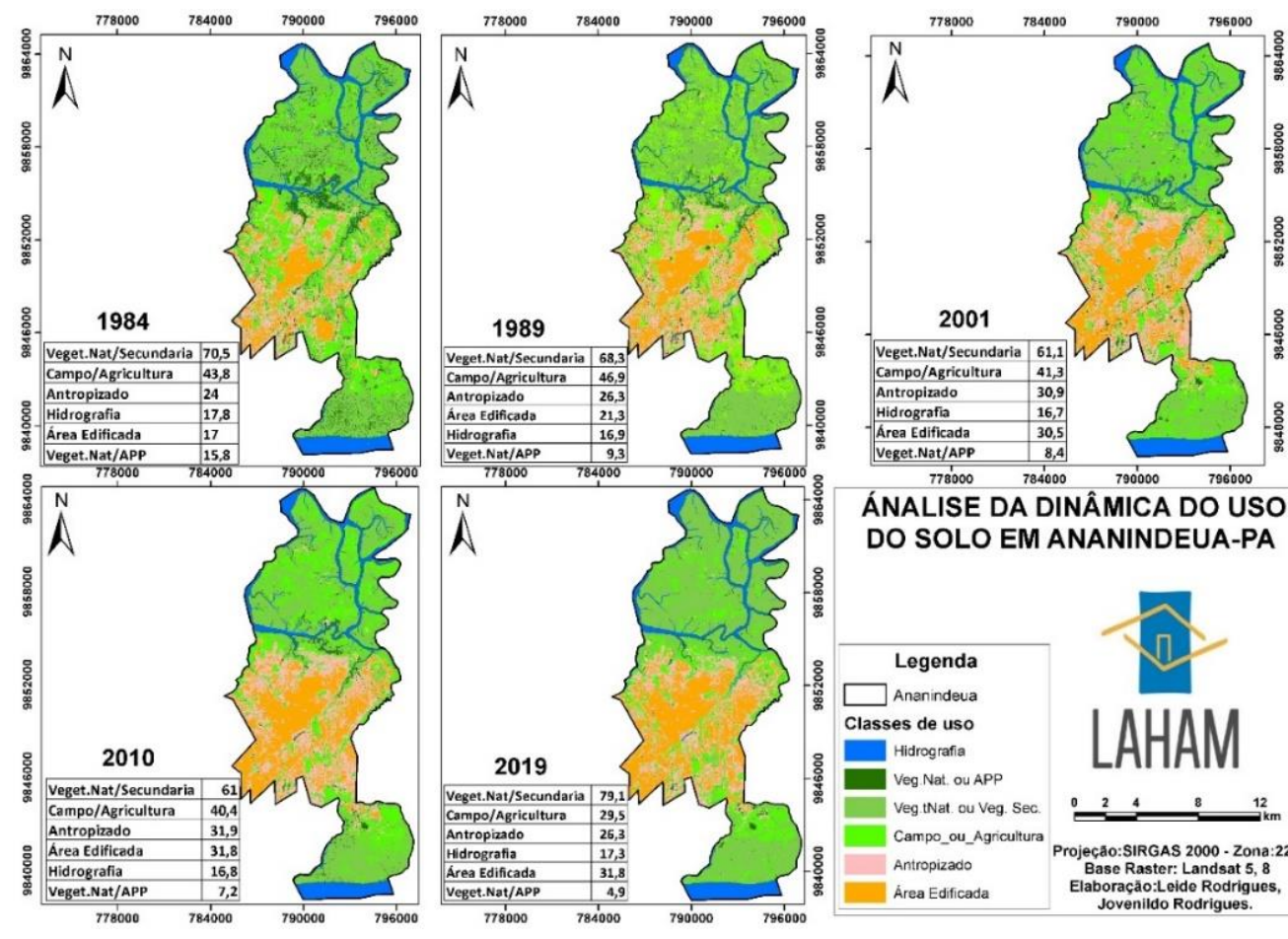

DO SOLO EM ANANINDEUA-PA

Fonte - Elaborado pelos autores do artigo.

O mapa da dinâmica de uso do solo do referido município, produzido a partir da captura de imagens de satélite, durante os referidos períodos históricos, permite identificar ainda uma redução de $28,57 \%$ da área destinada a atividade de campo/agricultura, quando comparamos o ano de $2001 \mathrm{com} o$ ano de 2019. O respectivo mapa de uso do solo permite ilustrar também uma redução significativa da vegetação natural das Áreas de Proteção Permanente (APP), que teve uma diminuição da ordem de 41\% do seu território, quando comparamos as imagens de satélite do ano de 2001 com 2019.

Os elementos apresentados na respectiva cartografia multitemporal, permite-nos evidenciar intensas mudanças no uso do solo urbano em Ananindeua, sobretudo a partir dos anos de 2000. A expansão da terra urbanizada na escala da cidade de Ananindeua está vinculada à nova condição espacial da mesma cidade, como território marcado por intensas disputas socioespaciais entre agentes produtores do espaço urbano (Estado, proprietários fundiários, construtoras, agentes imobiliários, agentes econômicos do terciário e terciário avançado vinculados ao circuito superior e inferior da economia, agentes sociais excluídos ou incluídos precariamente), no contexto de divisão social 
desigual do espaço, fato que demanda a constituição de centros comerciais e de serviços, bem como, de novas centralidade urbanas.

Figura 3 - Ananindeua (PA): Expansão da Mancha urbana de Ananindeua, 1985-2019.

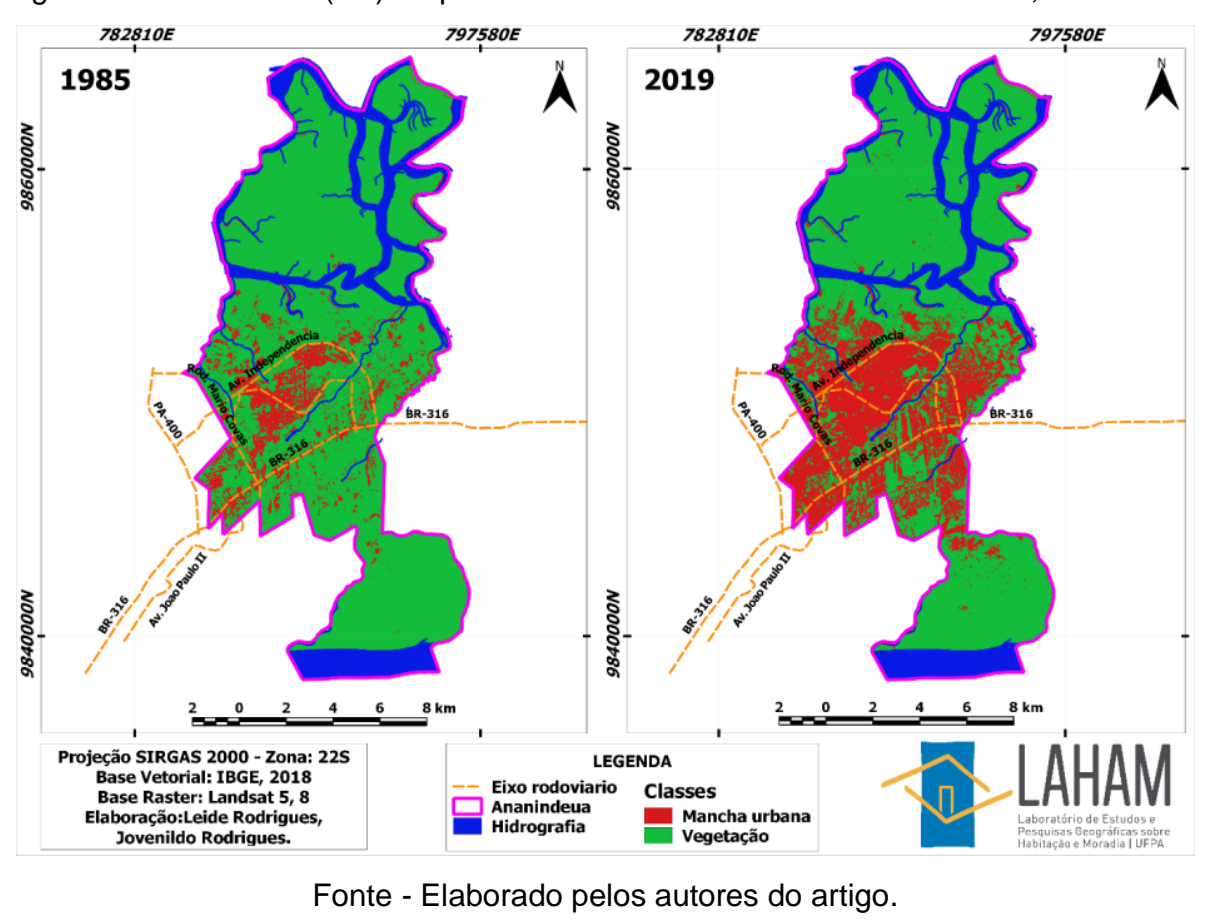

A Figura 3 (mapa) possibilita a identificação da expansão acelerada da mancha de Ananindeua, representada pela cor vermelha, assim como a diminuição significativa da vegetação primária e secundária no contexto do território municipal de Ananindeua, quando comparamos os anos de 1985 com o ano de 2019. Ao articularmos os dados demográficos que sinalizam o aumento vertiginoso do contingente demográfico da cidade com as imagens de satélite que ilustram a expansão da mancha urbana, tais elementos ajudam a entender não apenas o processo de antropização da vegetação, mas também permitem revelar o resultado do processo de urbanização do território e de restruturação da cidade, cuja espessura e expressões encontram-se evidenciadas nas novas paisagens urbanas com a presença de eixos estruturantes (BR-316, Avenida Mário Covas, Avenida Independência, Arterial 18) que potencializam novas formas de uso do solo urbano e a intensificação da divisão social desigual do espaço urbano ananindeuense, no contexto do processo de reestruturação da cidade.

A Figura 4 (mapa) permite ilustrar uma primeira característica da morfologia urbana de Ananindeua, relacionada a densificação do tecido de arruamentos, quando comparado o ano de $2000 \mathrm{com}$ ano de 2017, bem como, a presença e/ou fortalecimento de eixos estruturantes de Ananindeua (BR-316, Av. Independência, Av. Mario Covas, Arterial 18), enquanto formas urbanas implementadas com 0 propósito de induzir ou contribuir para maior centralidade e circulação de pessoas, mercadorias e serviços.

Neste sentido, o crescimento da circulação tende a contribuir para a redefinição e aumento do preço da localização do solo urbano, uma vez que espaços de maior circulação e centralidade são preteridos por agentes econômicos para a implantação de negócios (ABRAMO, 2001), contribuindo para o processo de valorização do espaço, para a constituição de centros e fortalecimento de novas centralidades urbanas. Assim, o Eixo da BR-316, no perímetro urbano de Ananindeua, apresenta o preço do metro quadrado mais elevado, quando comparado com os demais espaços da cidade. Segundo dados da Secretaria de Saneamento da Prefeitura Municipal de Ananindeua, o preço do metro quadrado as margens da BR-316, no perímetro urbano de Ananindeua, custa entre $\mathrm{R} \$ 150,00$ (14,35\% do salário mínimo de 2020) e $\mathrm{R} \$ 180,00$ (17,22\% do salário mínimo de 2020); ao passo que na Cidade Nova, o preço do metro quadrado varia entre $R \$ 12,00$ (1,15\% do salário mínimo de 2020) e $\mathrm{R} \$ 15,00$ (1,43\% do salário mínimo de 2020) (ANANINDEUA, 2019). 
Figura 4 - A nanindeua (PA): Eixos Estruturantes e Morfologia urbana, 2000-2017.

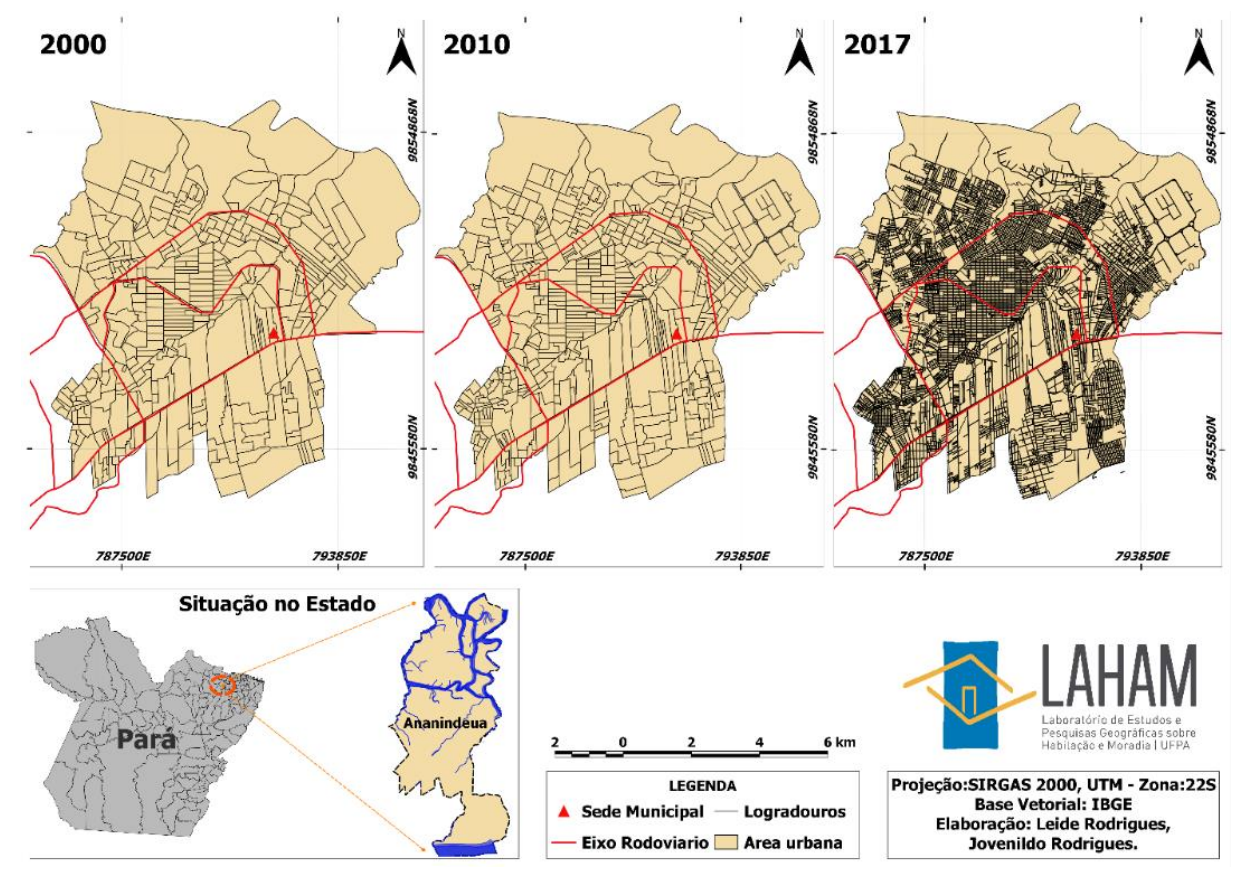

Outra reflexão importante identificada a partir das informações, contidas nas Figuras 3 e 4 (Mapas), diz respeito a mudanças na espessura do tecido urbano. Neste sentido, as imagens de satélite contidas nas cartografias produzidas (Figuras 3 e 4 ) e os 6 trabalhos de campo permitem evidenciar a existência de um padrão de organização espacial, com formas lineares e em malhas, nas áreas consideradas centrais da cidade (local onde estão localizados grandes empresas de comércio e serviços); ao passo que as franjas urbanas de Ananindeua tendem a apresentar um padrão de organização espacial "espontâneo" das suas ruas, frequentemente associado a ações de ocupação urbana antigas e recentes, cujas características não são marcadas necessariamente pela linearidade das ruas e eficiência dos padrões de ordenamento territorial aos interesses do Estado e do Mercado. Nestes espaços mais afastados das áreas centrais da cidade, é possível evidenciar fraca presença do Estado no sentido de constituição de um ordenamento territorial que possibilite melhor atendimento a demandas sociais dos moradores locais. A esse respeito, Lima; Oliveira; Souza (2020) enfatizam que modelos e práticas políticas pautadas em "urbanismo corporativo" conduzidas pelo Estado constroem uma janela de oportunidade para grandes agentes moduladores do espaço, contribuindo para promover a "captura da cidade enquanto negócio", operando uma sinergia entre o urbanismo corporativo, capital financeiro e instâncias estatais que acionam instrumentos jurídicos para supervalorização da propriedade privada em detrimento dos usos comum e popular.

\section{EIXOS ESTRUTURANTES E A NOVA CONDIÇÃO DE CIDADE MULTI(POLI)CÊNTRICA NA AMAZÔNIA PARAENSE?}

O espaço geográfico ananindeuense, no início do século XXI, constitui mosaico de espacialidades urbanas complexas, vinculadas a tempos histórico-geográficos, que se cristalizaram na produção do território da cidade como elementos do encontro e do desencontro de múltiplas e diversas paisagens urbanas que coexistem e se (re)produzem no contexto de dinâmicas da produção capitalista do espaço. A esse respeito, há que se ressaltar o papel do centro e da centralidade urbana como parte da produção do espaço da cidade, enquanto sínteses de múltiplas determinações inerentes à "metamorfose" socioespacial de Ananindeua.

O território da cidade, que outrora (anos de 1960) constituía-se a partir de um único centro tradicional (administrativo, comercial, de serviços), vinculado fortemente à produção agrícola e a ruralidades que se realizavam no contexto municipal, atualmente não pode ser compreendido sem considerarmos as mutações, espacialidades e coexistências inerentes às dinâmicas aceleradas dos eixos estruturantes

$\begin{array}{lllll}\text { Caminhos de Geografia } \quad \text { Uberlândia-MG } & \text { v. 22, n. } 81 & \text { jun./2021 } & \text { p. 106-126 } & \text { Página } 115\end{array}$


de Ananindeua. Dos centros e das novas centralidades urbanas da cidade emanam impulsos para sua hinterlândia (próxima e distante) e são impulsionadas por ordens distantes à região, como produto, meio e condição da mundialização do capital e dos processos de urbanização, de reestruturação urbana e da cidade (RODRIGUES; SOBREIRO FILHO; OLIVEIRA NETO, 2018).

Tendo em vista a necessidade de entendermos algumas dinâmicas inerentes à nova condição espacial do centro e das novas centralidades urbanas de Ananindeua, apresentaremos aqui uma proposta de tipologia para pensar a cidade de Ananindeua, ainda que entendamos que as tipologias possam incorrer em algum nível de fragilidade. Não obstante, a tipologia aqui apresentada não partiu de uma construção abstrata, mas de um conjunto de observações e investigações empíricas, a partir da qual se tornou possível fazer determinadas afirmações. Dito isto, propomos uma tipologia de estrutura interna da cidade, de maneira a pensar as novas configurações do Centro e da Centralidade na Cidade de Ananindeua, subdividido da seguinte maneira: 1) Eixo Estruturante da BR-316;2) Eixo Estruturante da Avenida Mario Covas; 3) Eixo Estruturante da Arterial 18; 4) Eixo Estruturante da Avenida Cláudio Sanders; e 5) Eixo Estruturante da Avenida Independência.

1) Ao longo do Eixo Estruturante da BR-316, é possível identificar pelo menos dois centros de comércio e serviços com forte poder de polarização, quais sejam: 1) O Centro tradicional (também denominado de centro administrativo, de comércio e serviços), localizado no Bairro do Centro, caracterizado pela presença da sede da prefeitura de Ananindeua, Igreja Matriz de Ananindeua, agentes dos circuitos superior da economia urbana - a exemplo do comércio atacadista de grande porte como os Hipermercados Assaí, Atacadão, Meio-A-Meio Preço Baixo, serviços como bancos, farmácias, clínicas de saúde, hospital, escolas de ensino fundamental e médio, além da presença de agentes do circuito inferior da economia. A configuração de novos centros e novas centralidades urbanas a partir de vetores de expansão e valorização do espaço, no qual há uma interação entre esses agentes, na produção do espaço, expansão urbana e metropolização, constituem processos que vem ocorrendo na Região Metropolitana de Belo Horizonte e Fortaleza, como destacado em Lages (2020) e Lopes (2019), respectivamente.

O Segundo Centro comercial e de serviços do Eixo da BR-316, no perímetro urbano de Ananindeua, encontra-se localizado ao longo dos quatro primeiros quilômetros da Conurbação BelémAnanindeua ${ }^{2}$. Este centro Expandido possui sua constituição e consolidação vinculada aos processos de (re)estruturação metropolitana e de reestruturação da cidade de Ananindeua, principalmente a partir dos anos de 2000, quando novos investimentos governamentais, o estímulo à presença de novos agentes econômicos (terciário e terciário avançado, comércio, serviços, construtoras, bancos, incorporadoras) passaram a se territorializar em busca de novos mercados consumidores, contribuindo para aceleração do processo de valorização do espaço, intensificação de diferenciações e aprofundamento de desigualdades socioespaciais. Neste sentido, a figura 5 permite evidenciar a presença de agentes do circuito superior da economia urbana, a exemplo do Castanheira Shopping Center, Lojas Americanas, Macro Atacadista, Supermercado Líder, Banco Itaú, além de concessionárias de veículos de marcas como Mercedes Benz, Toyota, Honda e General Motors.

Ainda para o Caso do Eixo Estruturante da BR-316, a espessura da morfologia dos dois centros que se "esparramam" ao longo do perímetro urbano de Ananindeua, constituem estruturas espaciais que apresentam funções de centralidade e polarização que ultrapassam a escala local, irradiando impulsos econômicos e interações espaciais em escala metropolitana, regional, nacional, ao mesmo tempo em que as "franjas urbanas" desta cidade são impactadas pelos efeitos da periferização e precarização das formas de moradia, trabalho e reprodução social. Melara; Silva (2018), ao analisar a policentralidade e a fragmentação urbana nas cidades médias de Resende e Volta Redonda, afirmam que tais processos que se capilarizam, reestruturam-se e interferem na posição de cidades médias na rede urbana brasileira (MELARA e SILVA, 2018), bem como na constituição de novos centros e novas centralidades urbanas.

\footnotetext{
2 Acerca deste último núcleo, convém ressaltar a expressiva concentração de filias de concessionárias, pertencentes a grandes corporações nacionais e internacionais, como: Honda, Motobel(tratores), Chevrolet, Mercedes-Benz/Rodobens, Nissan, Iveco (caminhões), KIA Motors, Renault, Ford, Fiat, Hyundai, Raviera Motors e Volkswagen, além de 5 agências bancárias, 2 supermercados, e um Shopping center (Shopping Castanheira).
}

$\begin{array}{lllll}\text { Caminhos de Geografia } \quad \text { Uberlândia-MG } & \text { v. 22, n. } 81 \quad \text { jun./2021 } & \text { p. 106-126 Página } 116\end{array}$


Figura 5 - Ananindeua (PA): Equipamentos urbanos de comércio, localizados às margens da BR-316, no perímetro da conurbação Belém- Ananindeua, 2019.

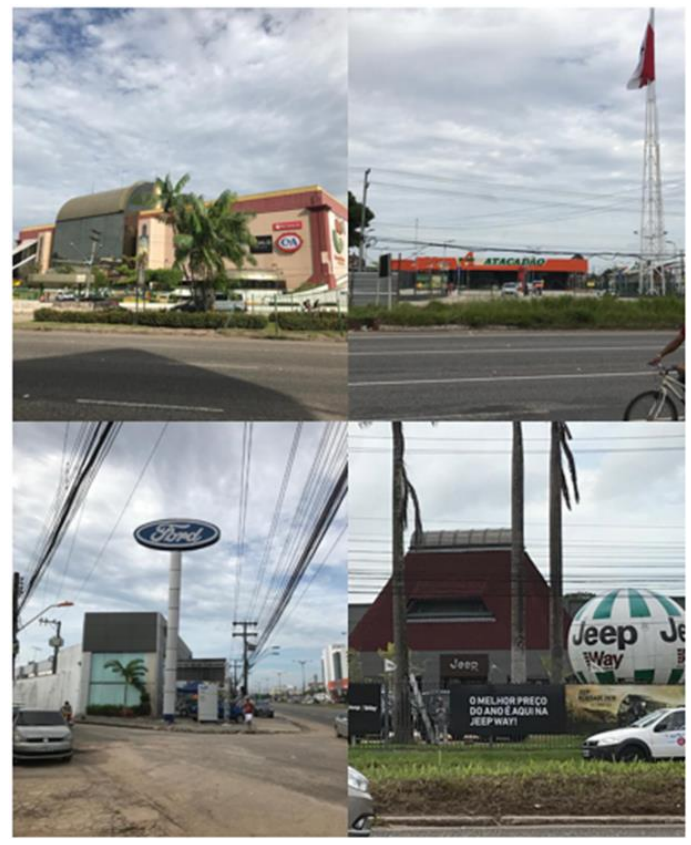

Fonte - Rodrigues, J.R. Trabalho de campo realizado em 3 de dezembro de 2019.

2) O Eixo Estruturante da Avenida Mário Covas apresenta, em suas paisagens urbanas, as marcas da segmentação socioespacial com diferentes usos do solo. Nas proximidades do entrecruzamento entre a BR-316 e a Avenida Mário Covas, é possível identificar a presença de um Centro de comércio e serviços, que tem como elemento representativo o Shopping Metrópole Ananindeua ${ }^{3}$. Além disso, há concessionárias de veículos de capital Local, regional, Nacional e internacional, Motéis, postos de gasolina, dentre outros estabelecimentos de comércio, como o Supermercado Cidade, o Supermercado Preço Baixo, Meio a Meio, assim como serviços hospitalares com a presença do Hospital Camilo Salgado e Hospital Público Estadual Galileu. O respectivo Eixo apresenta como característica marcante usos do solo urbano (comercial, residencial e misto), caracterizando-se por precarização da infraestrutura urbana, à medida que nos afastamos das áreas consideradas centrais, que possuem melhor infraestrutura, maiores fluxos de pessoas, mercadorias e serviços. O Eixo da Avenida Mário Covas possui um Centro com menor poder de polarização, quando comparado com os Centros do Eixo Estruturante da BR-316, não obstante, a presença de novos equipamentos urbanos como o Shopping Metrópole Ananindeua tem contribuído para o fortalecimento da centralidade urbana do respectivo Eixo Estruturante, tanto no contexto da cidade de Ananindeua, quanto na escala metropolitana.

3) Já o Eixo da Arterial 18, também denominada Avenida Dom Vicente Zico, localizada no Bairro do Coqueiro, apresenta um Centro comercial e de serviços bastante significativo. No referido Eixo Estruturante da Arterial 18, é possível identificar a presença de uma Centro de comércio e serviços, com presença de serviços Bancários (Banco do Brasil, Santander, Banco da Amazônia), Supermercados, além de dinâmicas de comércio atreladas aos circuitos inferior e circuito marginal da economia urbana. Vale destacar a presença de duas feiras Livres ao longo do referido Eixo estruturante, que possuem uma dinâmica de comércio de considerável relevância para o atendimento de demandas sociais das populações dos Bairros do Coqueiro, Guajará e PAAR.

Há que se ressaltar aqui o papel central que exercem as feiras livres no contexto da economia urbana em cidades amazônicas, como espaços em que a economia informal constitui, em muitos casos, a única forma de geração de renda para considerável parcela da população que, em um contexto de crise econômica, urbana e pandêmica, reproduz-se, resiste e sobrevive a partir de trabalho informal nas feiras da RMB. Estas modalidades de trabalho tendem a ser "eclipsadas" pela vida urbana 
hegemônica capitalista: um "eclipse dos espaços públicos da reunião e do encontro (em espaços vistos como improdutivos), da degradação do trabalho enquanto atividade humana, bem como dos lugares de trabalho, cooptação do tempo do lazer ao mundo da mercadoria" (CARLOS, 2020, p. 359). Nas proximidades da Arterial 18, especificamente na Travessa SN 3, podemos identificar a presença de importantes serviços educacionais, com presença da Universidade Federal do Pará (UFPA).

4) Por sua vez, no Eixo Estruturante da Avenida Cláudio Sanders, nas proximidades da confluência com o Eixo da BR-316, podemos encontrar um Centro comercial e de serviços, com forte presença de agentes, tanto do circuito superior quanto do circuito inferior da economia. A paisagem urbana desta área central tem como característica marcante a presença de pequenas lojas de confecções, lanchonetes, lojas de Crédito como a BMG, farmácia popular, coexistindo com grande rede supermercadista, como o Supermercado Mateus e com farmácia de capital nacional, como a Drogaria Pague Menos. A paisagem urbana da Avenida Cláudio Sanders revela feições singulares, referimonos à intensa presença de vendedores ambulantes que durante todos os dias da semana montam suas barracas para vender frutas, eletroeletrônicos importados, lanches, constituindo meio de sobrevivência desses segmentos sociais que não puderam se inserir no mercado de trabalho formal.

5) Já o Eixo da Avenida Independência apresenta-se como eixo ainda em processo de consolidação, com presença do terciário avançado, como o Hipermercado ASSAI, além de presença marcante de Condomínios residenciais fechados de médio e alto padrão, em suas proximidades. No eixo estruturante da Avenida Independência, podemos identificar as contradições da produção capitalista da cidade, revelada por uma paisagem urbana marcada por moradias precárias, pequenos estabelecimentos de comércio, ruas sem asfalto, coexistindo com condomínios de médio e Alto Padrão, elementos que permitem identificar diferenciações e desigualdades socioespaciais.

Figura 6 - Ananindeua (PA): Eixos Estruturantes e Equipamentos Urbanos, 2019.

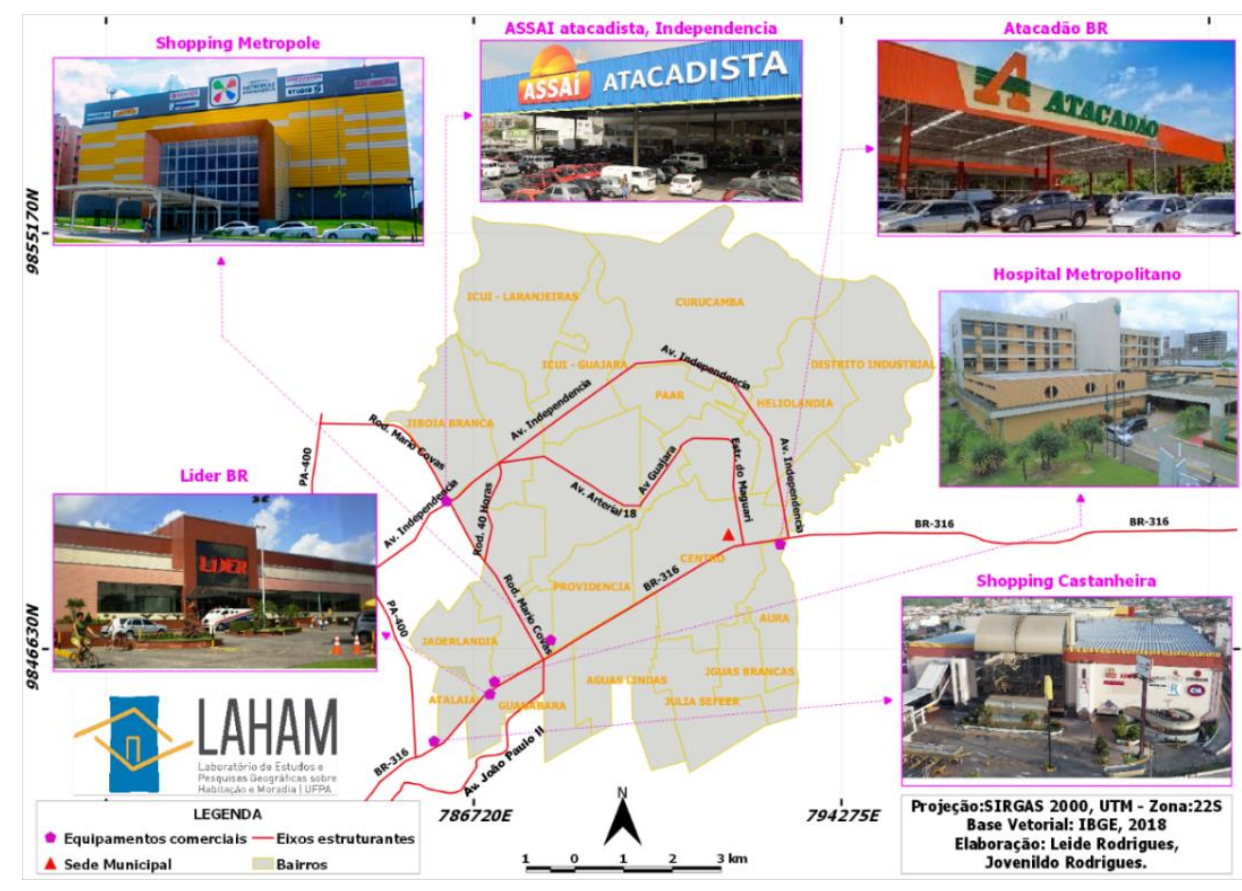

Para além dos referidos eixos estruturantes, é possível identificar a Avenida 3 Corações, nas proximidades da Praça da Bíblia, no Bairro do Coqueiro, como espaço que apresenta um centro e centralidade associada a funcionalidades comerciais, com presença de Bares, restaurantes, Academia, Hipermercado Formosa, dentre inúmeros estabelecimentos comerciais de pequeno porte, com forte dinâmica noturna.

A Figura 7 permite identificar a localização de alguns dos principais estabelecimentos de comércio varejista e atacadista de Ananindeua, como O Líder BR, o Shopping Castanheira, o ASSAÍ

$\begin{array}{llll}\text { Caminhos de Geografia } \quad \text { Uberlândia-MG } & \text { v. 22, n. } 81 \quad \text { jun./2021 } & \text { p. 106-126 Página } 118\end{array}$


Atacadista, Atacadão BR-316, assim como o Hospital Metropolitano, que constitui um importante estabelecimento de serviço público de saúde. A localização dos respectivos empreendimentos de comércio e serviços ao longo dos principais Eixos Estruturantes permite evidenciar não apenas estratégias dos agentes econômicos, mas também lógicas e racionalidades associadas ao consumo do espaço, localização-circulação inerentes aos interesses, por parte dos agentes econômicos, em se estabelecer nos espaços com melhor infraestrutura urbana e com maiores níveis de fluidez e acessibilidade.

As dinâmicas urbanas, vinculadas ao processo de reestruturação urbana e da cidade de Ananindeua, permite-nos pensar o que Pereira (2014) e Sposito (2010) entendem como a condição de poli(multi)centralidade ${ }^{3}$ urbana de Ananindeua, cujas expressões revelam-se em múltiplos centros e diversas centralidades urbanas, que irradiam seus feixes de interações espaciais para além dos limites municipais, como resultado do processo de metropolização, além da presença de novos agentes econômicos de capital nacional e internacional que passaram a se territorializar em áreas centrais desta cidade de porte médio, conformando um mosaico de espacialidades urbanas diversas e desiguais.

\section{NARRATIVAS REVELANDO CONTRADIÇÕES NA (RE)PRODUÇÃO DO CENTRO E DA CENTRALIDADE URBANA EM ANANINDEUA}

As metamorfoses na produção territorial da cidade de Ananindeua, evidenciadas na condição de poli(multi)centralidade desta cidade de porte médio, podem ser reveladas também quando consideramos o espaço vivido, a partir de suas práticas espaciais e experiências de moradores e representantes locais, que, ao acionarem suas memórias, tendem a resgatar algumas dinâmicas, significados, relações, conflitos e contradições na produção da centralidade desta cidade, nos últimos anos do século XXI.

A respeito do papel que essa cidade vem exercendo como provedora de serviços de educação pública superior, com a presença do Campus da UFPA-Ananindeua, o professor Francivaldo Nunes (Coordenador da Universidade Federal do Pará, Campus Ananindeua, e presidente do Fórum Municipal de Educação de Ananindeua) aponta justamente para a importância dos serviços públicos educacionais, no contexto de demandas sociais das populações que residem na cidade de Ananindeua e Região Metropolitana de Belém. Quando indagado sobre a importância do campus para a formação cidadã e para a nova condição de centralidade da cidade de Ananindeua, o referido entrevistado afirmou que:

Primeiramente, antes de qualquer coisa, eu sou morador de Ananindeua, sempre morei no município de Ananindeua desde quando vim do Maranhão pra cá. Cheguei aqui em 1990, eu tinha na época 18 anos e estou agora com 47, [...] e vim morar em Ananindeua. Vim sozinho, eu vim só pra estudar, pra fazer um curso superior e claro, também trabalhar, né?! Mas o objetivo central era continuar os meus estudos e aqui fiquei, terminei minha graduação e fui ficando. [...] vivenciei esse processo de alguma forma de crescimento da cidade de Ananindeua em um momento muito significativo, que foi o final da década de 1990 e início dos anos 2000, que foi quando recebemos aqui um quantitativo muito grande, seja de pessoas vindo do interior do estado, seja pessoas vindo de outros estados, né?! Eu vim nessa situação de estudar. Mas muitas pessoas que depois eu conheci, [...] vieram com família mesmo, já com esposa, com filhos e vieram pra morar aqui por conta das condições, principalmente. Aí a gente, um número grande de maranhenses, cearenses, piauienses, muita gente do Sul do Pará também vieram para Ananindeua, até pela questão dos conflitos agrários que a gente tinha de forma muito intensa na década de 90 e anos 2000. Aí esse crescimento muito grande dessas áreas mais afastadas do centro da cidade [...] eu acompanhei um pouco disso aí.

3. Segundo Sposito (2010), o termo é conferido aqueles espaços que, a partir da presença de grandes equipamentos urbanos (como é o caso do Shopping em questão, que exerce centralidade para além dos limites municipais), é redefinido de maneira profunda e acelerada. Estas redefinições perpassam pelas morfologias, formas e estruturas urbanas, chegando até à redefinição das classes sociais que residem nas circunvizinhanças do shopping, de maneira a nos remeter às questões relativas ao direito à cidade, justiça espacial e segregação socioespacial como processos que andam de "mãos dadas" com a territorialização desses novos agentes econômicos. 
A fala do professor também permite enxergar alguns elementos relativos às dinâmicas demográficas na escala intra e multiescalar, associadas ao ensejo do acelerado processo de estruturação urbana da cidade de Ananindeua, no final dos anos de 1990 e início dos anos 2000, bem como resgata de maneira bastante satisfatória a centralidade urbana irradiada por Ananindeua no momento de sua chegada. A sua fala inclusive converge bastante para o resgate das centralidades pretéritas que buscamos fazer em momento anterior, enquanto elemento que ajudou a pensar "a cidade como trabalho materializado ao longo de todo o processo histórico - objetivação do sujeito. Tal processo de produção continuada permite revelar o conteúdo da vida, bem como a produção enquanto movimento e (momento) que revela a prática espacial" (CARLOS, 2020).

Mostra-se, portanto, como um parâmetro interessante para pensar as dinâmicas urbanas dispersas dos dias atuais. Os elementos trazidos nas narrativas em exame são bem satisfatórios para a obtenção de uma panorâmica dos recentes processos de metamorfose do espaço ananindeuense, evocando algumas das multi(poli)centralidades desta cidade, no contexto de espraiamento do tecido metropolitano ananindeuense.

Nesse contexto, achamos relevante para a compreensão do processo de expansão da mancha urbana de Ananindeua destacar outro fragmento da fala do professor Francivaldo Nunes, quando ele nos revelou os elementos de preocupação e os procedimentos tomados em relação às novas instalações do campus, o qual se encontra em processo de edificação no bairro do Icuí-Guajará, uma vez que esse campus ainda está funcionando em um prédio alugado, onde até pouco tempo não dipunha de um espaço próprio.

[...] Nós estamos agora com as obras no lcuí-Guajará, [...], a ideia é que a gente receba até 2022 aproximadamente 4.000 alunos, 98 professores, 45 técnicos, fora o que a gente vai agregar de pessoas visitando a universidade. O transporte lá hoje não atende isso, então nós comunicamos para que as secretarias se planejem para essa situação. Do ponto de vista da segurança, nós fizemos o mesmo com a Policia Militar do Estado, informamos a necessidade da implantação de um posto de policiamento na frente do Campus, né?! $E$ a necessidade de rondas nas proximidades, até porque nós vamos estar recebendo alunos que irão desembarcar em paradas próximas, não necessariamente na frente, mas que precisam de uma segurança mínima para chegar até o campus. Então hoje a universidade tá preocupada com isso, há uma preocupação nesse sentido (Francivaldo Nunes, entrevista concedida dia 16 dez. 2019).

A perspectiva levantada pelo entrevistado é muito elucidativa no sentido de nos mostrar como a instalação de equipamento urbano deste porte exerce centralidade e, portanto, influência no processo de (re) estrutração da cidade, possibilitando o desenvolvimento de uma cidade dispersa e com os novos arranjos espaciais de crescimento atrelados a acessibilidades desiguais. Ou, como enfatiza Carlos (2020, p. 356): "Na cidade a reprodução promove a extensão do tecido urbano revelando a tendência da realização do valor de troca sobre o valor de uso no espaço como momento em que a troca suplanta o uso transformando-o em signo mudando profundamente o espaço e o tempo das atividades humanas".

Assim, é importante atentarmos aos detalhes e correlações por trás desse esgarçamento do tecido urbano ananindeuense, que representa, em última análise, a expansão dos diversos setores do capital, à medida em que, de acordo com Pereira (2014), não é um centro disperso que faz a cidade espandida, é o surgimento de outros centros ou, segundo o escopo deste trabalho, o sugimento de outros eixos centrais que possibilitam a emergência de uma cidade multi (poli) cêntrica (RODRIG|UES, 2020). Elemento importante para pensarmos a centralidade dos serviços educacionais de Ananindeua no contexto do território paraense, são os dados disponibilizados pela Pró-Reitoria de Ensino de Graduação -PROEG/UFPA, que demonstram o número de estudantes de outros municípios do Pará que se deslocam para estudar em Ananindeua, como pode ser demonstrado na tabela 2.

Tabela 2 - Ananindeua (PA): Origem municipal dos estudantes com vínculo ativo na UFPA, 2020.

\begin{tabular}{cc}
\hline Município de origem & Estudantes com vínculo ativo \\
\hline Altamira & 17 \\
Ananindeua & 924 \\
Curuçá & 61 \\
São João de Pirabas & 47 \\
Soure & 47 \\
Tucuruí & 51 \\
\hline
\end{tabular}

Fonte - Pró-Reitoria de Ensino de Graduação - PROEG/UFPA.

Caminhos de Geografia $\quad$ Uberlândia-MG $\quad$ v. 22, n. $81 \quad$ jun./2021 $\quad$ p. 106-126 
A memória e a fala de Driele Sousa, moradora da Cidade de Marituba (localizada na Região Metropolitana de Belém) e frequentadora cotidiana dos espaços de comércio e serviços na cidade de Ananindeua, muito nos diz acerca da redefinição da centralidade da cidade de Ananindeua, no âmbito do processo de metropolização e reestruturação urbana, evidenciando ainda em seu relato a conformação das novas expressões de centralidade urbana no âmbito do comércio e dos serviços.

\begin{abstract}
Nessa época natalina agora, há dez, quinze anos atrás, em Belém era muito inchado, todo mundo queria ir pro comércio. Esses quinze anos que eu estou me referindo, eu estou me lembrando da época de Icoaraci. Mas a minha vó sempre morou na região metropolitana, tipo Murinin, Benevides e agora Santa Bárbara. Ela sempre vinha do Murinin pro comércio de Belém pra comprar as coisas e era muito inchado, a gente fazia tipo assim: dia 10 de dezembro, a família toda ia pro comércio comprar as coisas, sabe? E agora a gente não faz mais questão de ir pro Ver-OPeso, ali pro comércio em Belém. A gente fica em Ananindeua, porque as lojas que antes só tinha lá, agora têm em Ananindeua. Outras fecharam mesmo e migraram pra Ananindeua. Eu lembro de uma loja que a vovó gostava de comprar sapatos [...] que fechou e abriu em Ananindeua. As pessoas estão deixando de ir mais, é muito sufoco e engarrafamento. Ninguém quer engarrafamento na vida. Pra quê passar sufoco se Ananindeua já tem quase tudo que a gente precisa, né?![...] Os moradores de Santa Bárbara e eu, por exemplo, só vou pra Belém pra resolver coisas que não existe em outro lugar, mas existindo em Ananindeua, tu fica em Ananindeua, né? (entrevista concedida por Driele Sousa em 06 dez. 2018).
\end{abstract}

A narrativa mostra-se interessante para observarmos o acelerado movimento de reestruturação da cidade e formação de novas centralidades do comércio e dos serviços na escala da Região Metropolitana de Belém. Nesse sentido, por meio de um breve resgate na memória dos espaços de experiências, a entrevistada relata a sua dinâmica cotidiana e suas práticas espaciais, ajudando-nos a pensar o movimento de metamorfose do espaço vinculado ao processo de reestruturação e suas reverberações nas práticas espaciais de citadinos, sobretudo a partir dos anos de 2000.

Outro ponto de relevância, no que concerne à análise da narrativa, refere-se à questão dos transtornos ocasionados pelos engarrafamentos, que como se sabe, fazem parte da rotina das grandes metrópoles vinculadas à precariedade da mobilidade urbana na RMB. A esse respeito, a entrevistada profere com certa ênfase a seguinte retórica: "Ninguém quer engarrafamento na vida. Pra quê passar sufoco se Ananindeua tem tudo que a gente precisa, né?!". Por sua vez, a fala de Alexandre Silva (Diretor de fiscalização da Secretaria de Gestão Fazendária-SEGEF do município de Ananindeua). converge, nesse primeiro momento, com os relatos de Driele Sousa quando, ao indagamos acerca da importância da "Nova BR" (BRT) para o município de Ananindeua, evidencia o processo de reestruturação das formas e funções urbanas da cidade ao longo dos últimos anos:

O eixo da BR, ele cresce em torno do prédio da prefeitura, mercado municipal e de grandes empresas que ficam aproveitando a janela. Inclusive, atualmente nós temos essa obra estruturante no município, ela vai interligar a área metropolitana todinha, né?! Que é a reclassificação-requalificação da BR, o termo usado não é BRT, é a NOVA BR. Estão sendo construídas as estações, que são terminais rodoviários, teremos um elevado que vai fazer a interligação de um hemisfério da Cidade Nova com o outro, provavelmente ele vai sair do lado da AABB e vai atravessar para o lado do Julia Seffer. É esse que é o cenário. Então, aproveitando o embalo, todas as empresas, percebendo este melhoramento da via, estão tentando se estruturar, se posicionar ao longo da BR. Então, existe uma perspectiva de que o cenário inverta ou pelo menos se equilibre em relação ao Eixo da Cidade Nova. [...] Bom, ela vai permitir a integração dos moradores. Antes, há algum tempo atrás, Ananindeua era considerada como cidade dormitório, então, hoje, já é possível conhecer pessoas que dizem que não vão em Belém porque todos os serviços já são oferecidos dentro do próprio município e assim também deve acontecer em Marituba.(Entrevista concedida por Alexandre Silva no dia 29 nov. 2019).

Outro ponto merece destaque na fala do diretor de fiscalização fazendária. Refere-se à construção do BRT ou "Nova BR", como o próprio se reporta à obra. Ao mencionar a respectiva obra, Alexandre deixa implícito em sua fala que a importância ultrapassa a função de interligar as cidades pertencentes à RMB e que existem interesses subjacentes a ela. Esta impressão fica nítida, quando no momento da entrevista ele profere que as empresas (de vários segmentos), ao perceberem o melhoramento da via, procuram se estruturar ao longo da BR-316. Ainda segundo Alexandre Silva, o Eixo da BR-316 hoje não se mostra como principal centro de comércio e serviços, mas sim a rodovia do Coqueiro, no bairro da Cidade Nova. Por sua vez, a entrevistada Driele Sousa entende o principal eixo estruturante do ponto de vista do comércio e dos serviços de maneira diferente. 
Faz oito anos que a nossa família mora em Santa Bárbara, e a partir de então eu estou percebendo dentro do ônibus que as pessoas deixaram de ir pra Belém, porque Belém deixou mais de ser o centro, né?! O centro de comércio, o centro pra resolver as coisas. Isso vem mudando gradativamente, e mais ou menos de uns três anos depois da construção dos atacadões isso se intensificou e Ananindeua passou a ser uma Belém na vida, né?! [...] A questão comercial, bancária, a questão de emprego também [...] Ali aquele centro, a rua do Maguari, é ótimo pro comércio, é cada "shoppinzinho" popular, loja popular! Aquilo ali foi construído de oito anos pra cá, porque não tinha isso, era comércio mas não era do jeito que tá. $E$ quando a gente vem no ônibus, a maioria das pessoas descem em Ananindeua, tanto que o ônibus fica seco, e só vai pra Belém pessoas que realmente, tipo: trabalhadoras domésticas, que trabalham naqueles prédios em Belém de classe média e alta; pessoas como motoristas particular ou pessoas que trabalham na construção civil [...] é essa a característica de pessoas que tu vê dentro do ônibus de manhã cedo. Aí, 9 horas tu já vê no ônibus o pessoal que já vai pro comércio mesmo em Ananindeua, que vem especificamente pra resolver alguma coisa no banco, que vem especificamente resolver alguma coisa no cartório [...] porque em Ananindeua tem vários bancos, né?! Os bancos principais se encontra em Ananindeua e eles são muito populosos, as pessoas formam filas enormes ali na Caixa pra resolver coisas que tu até poderia resolver em Benevides ou em Marituba. Mas se a pessoa for sacar dinheiro, a pessoa vai direto pro Atacadão lá na frente da Caixa, se ela for comprar roupa, ela vai pra rua do Maguari, tá entendendo? Então assim, se for contar por exemplo, o Banco de Santa Bárbara é o de Ananindeua. Porque tem também a questão do NIS e Bolsa Família, é na Caixa aqui de Ananindeua. Qualquer coisa que tu tem que resolver no teu NIS [Número de Identificação Social] lá em Santa Bárbara, eles te mandam pra Caixa de Ananindeua, então tá centralizado porque até mesmo em Benevides não tem tudo que tem aqui [...]. Uma característica desse movimento é os ônibus que vêm de 6 horas, 7 horas e 9 horas, pode vir ver! O ônibus esvazia ali em frente à prefeitura, os poucos que ficam sentados vão pra São Brás (entrevista com Driele Sousa, concedida em 6 dez. 2018).

A fala dos dois entrevistados se cruzam quando Driele Sousa ressalta que a presença dos atacadões (segmento do ramo alimentício) potencializou a redefinição da centralidade exercida por Ananindeua no âmbito do comércio e serviços. Nossas observações nos levam ao entendimento de que as infraestruturas urbanas/fundiárias vêm se apresentando como um "tentáculo", resultante da produção capitalista da cidade, tendo como agente estruturador de grande relevância o poder público. Tal entendimento é reforçado, em outro momento, na fala do diretor de fiscalização fazendária, quando Ihe fizemos as seguintes perguntas:

P - Para além disso, você conseguiria identificar e enumerar cinco ou dez estabelecimentos maiores que se instalaram recentemente e que exercem significativa importância para o município?

R - Nós temos o Grupo Matheus, o Assaí, o Carrefour, que é o Atacadão BR, que se instalou recente, temos as torres de telefonia também, que hoje em dia não se faz mais nada sem wi-fi, né?! E que também permite que empresas ofertem seus serviços, não só dentro do próprio município, mas por todo o Brasil e mundo, né ?! [...] Tem também as grandes construtoras também, que já passaram por aqui, tipo a Libi, a Cirela, né?! [...] em algum momento atrás, salvo engano 2012, 2013, nós tivemos um boom imobiliário, aí, era um mercado novo e a Cirela chegou a construir o Eco Park, O Pleno... e assim também outras empresas como a Leal Moreira passou por aqui. [...]. E as empresas de engenharia, elas movimentam o cartório, aumentam a arrecadação do município, geram emprego, estimula o consumo, desse consumo a pessoa vai pagar o ICMS [Imposto sobre Circulação de Mercadorias e Serviços]. [...] isso é importante tanto pro estado quanto para o município em termos de arrecadação [...] (Entrevista concedida por Alexandre Silva no dia 29 nov. 2019).

$P$ - Você saberia nos dizer quais são hoje as principais empresas de comércio e serviços que atuam aqui em Ananindeua?

$R$ - Todos os atacadões que chegaram têm um peso aqui no município, e elas são geradoras de emprego. A exemplo do que ocorreu no Shopping Metrópole. Inclusive, para que o shopping pudesse se instalar foi oferecido um benefício fiscal para que ela pudesse se instalar gerando emprego, contratação de mão de obra local, utilização dos serviços das próprias empresas estabelecidas no próprio município [...] existe uma política do município, no sentido de atrair essas grandes empresas, sim. [...] o shopping Metrópole Ananindeua teve esses benefícios. Tem algumas 
empresas também que são construtoras de prédios de moradia popular também que elas pleiteiam, e uma vez atendidos requisitos elas têm desconto no ISS [Imposto Sobre Serviços], pagamento de IPTU [Imposto sobre a Propriedade Predial e Territorial Urbana], e que também é transferido para quem adquire o imóvel, para quem possui uma renda de até três salários mínimos [...] é uma forma de pensar na distribuição populacional dentro do município e gerar emprego e movimentar a economia.

As narrativas de Alexandre Silva, Francivaldo Nunes e Driele Sousa, permitem evidenciar as profundas metamorfoses socioespaciais pelas quais a cidade de Ananindeua vem passando, diante do processo de reestruturação urbana, metropolização do espaço, a partir da territorilização de novos agentes econômicos de comércio de capital nacional e internacional na estruturação da cidade, bem como, o papel dos novos centros de comércio e serviços na constituição da multi(poli)centralidade exercida por Ananindeua .

As aceleradas mudanças na morfologia urbana de Ananindeua revelam não apenas transformações nas paisagens e estruturas da cidade, mas intensificação de processos de aglomeração urbana e (re)produção desigual do espaço da cidade. A morfologia urbana de Ananindeua enquanto resultado da estruturação da cidade revela centros e centralidades urbanas pretéritas, coexistindo com novas centralidades, que apresentam articulação com níveis diferentes de urbanização, enquanto fusão do passado e do presente em movimento e reprodução.

Com efeito, a morfologia urbana de Ananindeua, os centros e as novas centralidades urbanas lidas em múltiplas escalas e em sua articulação com diferentes níveis de urbanização, enunciam a incorporação desta cidade a uma tendência mundial de novas formas de divisão socioespacial funcional das cidades, cuja tomadas de decisões por grupos dominantes, interferem no planejamento urbano e na construção de novas centralidades, baseadas em relacionamentos comerciais e na lógica de funcionalidade (BEUF, 2020) para atender a produção e o consumo capitalista.

\section{CONSIDERAÇÕES FINAIS}

Os territórios de cidades vêm passando por transformações profundas e complexas, como resultado de sucessivas crises do capitalismo com reverberações em múltiplas escalas da sociedade mundial. As espacialidades urbanas de Ananindeua, no período atual, revelam a presença do moderno e do tradicional, do rural e do urbano, de temporalidades e espacialidades pretéritas e atuais, de movimentos e ritmos, de funcionalidades e processualidades, que permitem evidenciar a diversidade do urbano na Amazônia metropolitana. Nesta perspectiva, o acelerado processo de urbanização do território, de reestruturação urbana e reestruturação da cidade associados a ações do Estado, bem como à territorialização de novos agentes econômicos em áreas centrais da cidade, vêm contribuindo para a (re)produção de "metamorfoses" socioespaciais, com presença de paisagens urbanas em áreas centrais nas quais evidenciam-se melhor infraestrutura urbana de comércio e de serviços, ao passo que a franja urbana de Ananindeua reproduz-se fugazmente, num contexto de precariedades de equipamentos de infraestrutura e privações de serviços urbanos fundamentais para a reprodução de condições dignas de vida.

As respectivas dinâmicas urbanas desta cidade paraense revelam uma nova condição espacial, como espaço que apresenta múltiplos centros e diversas centralidades urbanas, sobretudo quando correlacionamos às novas formas e morfologias urbanas da cidade, ao avanço de novos agentes econômicos de capital nacional e internacional. A territorialização desses novos agentes econômicos, que atuam em múltiplas escalas, tendem a impor um conjunto de lógicas e racionalidades, as quais vem interferindo profundamente na morfologia e na estruturação da cidade de Ananindeua, seja por intermédio da constituição de um mercado de terras e de rendas fundiárias urbanas, seja por dinâmicas de funcionamento e reconfiguração de centros e novas centralidades urbanas, conformando uma cidade multi(poli)cêntrica.

Os elementos quantitativos e qualitativos apresentados, ao longo desta pesquisa, nos ajudaram a entender as centralidades urbanas dos seus principais eixos estruturantes de comércio e serviços urbanos. Não obstante, a cidade de Ananindeua guarda em suas "entranhas" a existência de um conjunto de centralidades não reveladas e silenciadas na informalidade dos barqueiros que transportam pessoas das ilhas para a cidade cotidianamente, dos barraqueiros, vendedores de lanche, fruteiros e verdureiros, cuja vida urbana refaz-se cotidianamente pela economia informal, nas feiras livres dos bairros que anunciam sociabilidades e valores de usos e contra-usos na/da cidade, como forma de enunciar (sobre)vivências, resistências e conflitos por uma vida urbana justa e menos desigual. 
Para além de sua condição de "cidade para o capital", Ananindeua possui uma outra face, a de "cidade para o cidadão", cuja manifestação se dá pela condição de espaço que exerce importância fundamental, como provedora de comércio e de serviços urbanos não apenas para os cidadãos do referido município, mas também para outras populações de municípios da RMB, e do nordeste paraense. Tais elementos permitem pensar Ananindeua como uma "Cidade de Responsabilidade Territorial" em razão da importância exercida pela mesma, no contexto de atendimento às demandas sociais básicas de populações paraenses, tão carentes de serviços urbanos.

As reflexões apresentadas ao longo desta pesquisa possibilitaram apreender determinadas dinâmicas de produção territorial da cidade de Ananindeua. Não obstante, considerando as aceleradas mutações da cidade e do espaço metropolitano de Belém, emergem questões como pistas para futuras pesquisas, quais sejam: De que maneira a presença de novos agentes econômicos vem interferindo nas dinâmicas territoriais de municípios e cidades médias e pequenas da Amazônia Paraense? Como os circuitos da economia urbana vem se reproduzindo no espaço das cidades paraenses, diante das recentes determinações da produção capitalista do espaço e suas manifestações no território das cidades amazônicas?

\section{REFERÊNCIAS}

ABRAMO, P. Mercado e ordem urbana: do caos à teoria da localização residencial. Rio de Janeiro: Bertrand Brasil, 2001.

ANANINDEUA, Prefeitura Municipal. Lei n.․ 2.237, de 06 de outubro de 2006. Institui o Plano Diretor do Município de Ananindeua e dá outras providências. 59 f. Ananindeua: Prefeitura Municipal, 2006.

BECKER, B. K. Geopolítica da Amazônia: a nova fronteira de recursos. Rio de janeiro: ZAHAR Editores, 1990.

BEUF, A. Centralidad y policentralidad urbanas: interpretaciones, teorías, experiências. Espiral, v.1, n. 2, p.131 - 155, 2020. https://doi.org/10.15381/espiral.v1i2.17135

CARLOS, A. F.A. Henri Lefebvre: o espaço, a cidade e o "direto à cidade". Revista Direito e

Práxis, v.11, n.1, p.349-369, 2020. https://doi.org/10.1590/2179-8966/2020/48199

CORRÊA, R. L. A periodização da rede urbana da Amazônia. Revista Brasileira de Geografia, v.4, n.3, p.39-68. 1988.

CAPEL, H. La Morfologia de la cuidad. Barcelona: Editora Del Serbal, 2013.

HARVEY, D. La dialéctica. Territorios, v. 39, p. 245-272, 2018.

https://doi.org/10.12804/revistas.urosario.edu.co/territorios/a.6935

HARVEY, D. A Loucura da Razão Econômica. São Paulo: Boitempo, 2019a.

HARVEY, D.. Realization crises and the transformation of daily life. Space and Culture, v. 22, n. 2, p. 126-141, 2019b. https://doi.org/10.1177/1206331218786668

KEIL, R. Extended urbanization, "disjunct fragments" and global suburbanisms. Environment and Planning D: Society and Space, v. 36, n. 3, p. 494-511, 2018.

https://doi.org/10.1177/0263775817749594

LAGES, S. S. Políticas públicas, valorização da terra e metropolização: RMBH e o vetor industrial de expansão. Cadernos Metrópole, v. 22, n. 47, pp. 193-214, 2020. https://doi.org/10.1590/22369996.2020-4709

LEFEBVRE, H. The Production of space. Cambridge: Blackwell Publishers, 1991.

LEFEBVRE, H. Dissolving City, Planetary Metamorphosis. Environment and Planning D: Society and Space, v. 32, p. 199-202, 2014. https://doi.org/10.1068/d3202int

LIMA, A. N. V.; OLIVEIRA, L. S. V.; SOUZA, M. J. A. O Direito nas trincheiras da cidade: urbanismo corporativo e práticas contra-hegemônicas. Revista Direito e Práxis, v. 11, n. 1, p. 612-644, 2020. https://doi.org/10.1590/2179-8966/2020/48189

LOPES, F. C. R. Metropolização e policentralidade em Fortaleza (CE - Brasil). Revista GeoNordeste, v. 30, n. 3, p. 76-92, 2019. 
MELARA, E. SILVA, W. R. Elementos para refletir sobre a policentralidade e a fragmentação urbana em cidades médias - Resende e Volta Redonda (RJ). Confins [Online], v.38, s.p. 2018. https://doi.org/10.4000/confins.16121

MIYAZAKI. V. K. Morfologia Urbana e Estruturação da Cidade em Ituiutaba - MG: Análise das transformações no período de 2000-2018. Brazilian Geographical: Geosciences and Humanities Research Medium. v.9, n.1, p.23-39, jan/jun, 2018.

MONTE-MÓR, R. L. de M. Urbanização extensiva e lógicas de povoamento: um olhas ambiental. In: SANTOS, M. et. al. (Org.). Território, globalização e fragmentação. São Paulo: HUCITEC, 1998.

MOREIRA, E. Belém e sua expressão geográfica. In: MOREIRA, Ediorfe. Obras reunidas de Ediorfe. Belém: CEJUP, 1989.

PENTEADO, A. C. R. Problemas da colonização e uso da terra na Região Bragantina do Estado do Pará. Belém: UFPA, 1967.

PEREIRA, C. S. S. Centro, centralidade e cidade média: O papel do comércio e serviços na reestruturação da cidade de Juazeiro do Norte/CE. Dissertação (Mestrado em Geografia) Presidente Prudente: UNESP, 2014.

RIBEIRO, W. O. Interações espaciais na rede urbana do Nordeste do Pará: particularidades regionais e diferença de Bragança, Capanema e Castanhal. Tese (Doutorado em Geografia) - Presidente Prudente: UNESP, 2017.

RODRIGUES, E. J. Banidos da Cidade, Unidos na Condição: Cidade Nova - espelho da segregação social em Belém. Belém: UFPA/NAEA, 1998.

RODRIGUES, E. B. Aventura urbana: urbanização, trabalho e meio ambiente em Belém. Belém: NAEA, 1997.

RODRIGUES, L. L. C. Novas expressões do centro e da centralidade urbana: o papel dos agentes de comércio e serviços na (re)estruturação da cidade de Ananindeua, Pará. Dissertação (Mestrado em Geografia) - Belém: UFPA, 2020.

RODRIGUES, J. C.; SOBREIRO FILHO, J.; OLIVEIRA NETO, A. O rural e o urbano na Amazônia metropolitana: reflexões a partir de Ananindeua, Pará. Revista NERA, v. 21, n. 42, p.256-280, 2018.

RODRIGUES, J. C. Produção das desigualdades socioespaciais em cidades médias amazônicas: análise de Santarém e Marabá, Pará. Tese (Doutorado em Geografia) - Presidente Prudente: UNESP 2015.

SANTOS, M. A natureza do espaço: técnica e tempo, razão e emoção. São Paulo: Editora da Universidade de São Paulo, 1996.

SCOTT, A. S. M. The nature of cities: the scope and limits of Urban Theory. International journal of urban and regional research, v. 3939, n. 1, p. 1-15, 2014. https://doi.org/10.1111/1468-2427.12134

SOJA, E. W. Geografias pós-modernas: a reafirmação do espaço na teoria social. Rio de Janeiro: Jorge Zahar, 1993.

SPOSITO, M. E. B. Morfologia urbana. In: SPOSITO, E. S. (Org.). Glossário de Geografia Humana e Econômica. São Paulo: Editora Unesp, 2017.

SPOSITO, M. E. B. Segregação socioespacial e centralidade urbana. In: VASCONCELOS, P. A. CORRÊA, Roberto Lobato; PINTAUDI, S, M. (org.). A cidade contemporânea: Segregação espacial. São Paulo: Contexto, 2013. p. 61-93.

SPOSITO, M. E. B. Multi(poli)centralidade urbana. In: SPOSITO, E. S.; SANT'ANNA NETO, J. L. (Org.). Uma Geografia em Movimento. São Paulo: Expressão Popular, 2010, p. 199-228.

SPOSITO, M. E. B. O chão em pedaços: urbanização economia e cidades no Estado de São Paulo. Tese (Livre Docência em Geografia) - Presidente Prudente: UNESP, 2004. 
WEINSTEIN, B. A borracha na Amazônia: expansão e decadência, 1850-1920. São Paulo: Edusp/Hucitec, 1993.

VIEIRA, D. C. M.; RODRIGUES, J. C.; RODRIGUES, J. C. Mapeamento e análise de desigualdades socioespaciais: abordagem interpretativa a partir da cidade de Belém, Pará. GEOSABERES-Revista de Estudos Geoeducacionais, v. 9, n. 17, p. 1-21, 2018.

https://doi.org/10.26895/geosaberes.v9i17.612

Recebido em: 02/06/2020

Aceito para publicação em: 16/09/2020 